Mundo Agrario vol. 18, n 37, e039, abril 2017. ISSN 1515-5994

Universidad Nacional de La Plata.

Facultad de Humanidades y Ciencias de la Educación.

Centro de Historia Argentina y Americana

\title{
Juventudes rurales, conflicto generacional y políticas sociales
}

\author{
Rural youth, generational conflict and social policies
}

\author{
Santiago Rebollo *; Rafael Antonio Carreras **
}

\section{PALABRAS CLAVE}

Juventudes

Conflicto Generacional

Políticas Sociales

Semirrural

KEYWORDS

Youth

Generational Conflict

Social Policies

Semi-rural
* Universidad Nacional de Córdoba - Centro de Investigaciones y Estudios sobre Cultura y SociedadCONICET; ** Universidad Nacional de Córdoba, Argentina | psantirebollo@gmail.com; carrerasr@gmail.com

\section{RESUMEN}

Este artículo presenta los resultados de un proceso de investigación en un espacio semirrural donde se evidenciaron cotidianamente situaciones de conflictividad entre generaciones jóvenes y adultas en el espacio público. Estos conflictos, condicionados por aspectos sociales-culturales, políticos y económicos, repercutieron significativamente en las posibilidades y proyectos de los sujetos sociales implicados. En este marco, nos propusimos conocer los modos de relación intergeneracional para aportar al diseño de políticas sociales que promuevan procesos colectivos de resolución de conflictos comunitarios. Desde una metodología cualitativa, específicamente la investigación acción, accedimos a diversas experiencias y prácticas que nos permitieron arribar a una serie de aspectos relativos al conflicto en el espacio público y algunas claves a tener cuenta para el diseño de políticas sociales.

\section{ABSTRACT}

This article presents the results of a research process in a rural area where situations of conflict between younger and older generations in public spaces are evidenced daily. These conflicts, conditioned by social, political, economic and cultural aspects, impacted significantly on the possibilities and projects of social subjects involved, by hindering the production of capital for an intergenerational social reproduction to ensure healthy lifestyles. In this context we propose to know the ways of intergenerational relationship to design social policies that promote collective processes of community conflict resolution. From a qualitative methodology, specifically action research, we had access to various experiences and practices that allowed us to arrive at a number of dimensions related to the conflict in the public space to be counted as empirical support for the design of social policies. 


\section{Introducción}

Este artículo presenta los hallazgos de un proceso de trabajo realizado en el noreste de Córdoba, Argentina. El objetivo principal es contribuir a formas de resolución de conflictos entre generaciones jóvenes y adultas en el espacio público, en un contexto semirrural.

La experiencia con la comunidad de Villa Lucía se desarrolló durante el año 2011 y parte del 2012. El trabajo de campo se asentó en un diseño de tipo cualitativo (Valles, 2003; Vasilachis de Gialdini, 2009) dentro de la línea de investigación etnográfica (Das y Poole, 2008; Vasilachis de Gialdini, 2009; Guber, 2001) y acción participativa (Chávez Méndez y Daza Sanabria, 2003; Sánchez Vidal, 2003-2007a; Fals Borda, y Rodríguez Brandao, 1987) donde confluyen aportes centralmente de la psicología comunitaria.

Se combinaron diferentes técnicas en la investigación tales como talleres, espacios formativos, entrevistas, diálogos informales, encuentros espontáneos, espacios de organización comunitaria-política y planificaciones, entre otras, que posibilitaron comprender las cosmovisiones de los actores involucrados. Las técnicas de registro de información fueron variando según la pertinencia del momento del proceso, así, se utilizaron notas de campo, observación, observación participante, entrevistas semiestructuradas, y fuentes secundarias, como actas, libros, proyectos, boletín mensual y otras producciones de la gestión comunal.

Cabe subrayar que el foco de la pesquisa se centra en las interacciones que se desenvuelven en el espacio público porque es el conflicto entre jóvenes y adultos en este espacio lo que emerge como problemático. Entendemos que el espacio público constituye un escenario de apropiación e identificación multiactoral, un "lugar de lazo colectivo" (Corea, Aldea, y Lewkowicz, 1998) que "supone dominio público, uso social colectivo y multifuncionalidad por su fuerza mixturante de grupos y comportamientos, y por su capacidad de estimular la identificación simbólica, la expresión y la integración cultural” (Borja, 1998, p. 02). Pero también este espacio se configura en el "...trenzamiento de subjetividades e intereses co-presentes que coinciden episódicamente en lo que es -o debería ser- un horizonte abierto, intermitente, poroso y móvil...” (Delgado, 1999, p. 205). Estos procesos de apropiación en escenarios donde se expone lo personal y se constituye lo colectivo, posibilitan pensarlo como un espacio donde los conflictos, el poder y las negociaciones se redefinen continuamente entre los grupos sociales (Delgado, 1999).

Estas perspectivas nos permitieron centrar la atención sobre aquellos conflictos intergeneracionales que se presentan en un espacio relacional que se anuda con lo colectivo, lo cual rompe con la tradicional división entre lo público y lo privado. De este modo, las calles, la plaza, la esquina, el club o la escuela en sí mismos no garantizan el status de lo público, porque en las calles o en la plaza pueden existir conflictos que por su naturalización o latencia no se enlazan con lo colectivo. O bien, aquello que tiene status de "privado" por desarrollarse puertas adentro de la vivienda puede tomar estado público al transcender estas fronteras y enlazarse con el colectivo próximo (por ejemplo, violencias, trabajos clandestinos). Es decir, entendemos al espacio público no en contraposición con otro espacio u ordenamiento, sino como un espacio relacional anudado a las lógicas de poder que operan en esa comunidad de sentido.

En Villa Lucía los espacios públicos poseen nombre propio, son de la Comuna o de algún otro actor. Además visualizamos cierta reclusión en el espacio privado, pero a esto se le debe atribuir alguna relatividad, ya que, como señala el popular dicho "pueblo chico infierno grande", el ámbito de lo privado forma parte de la novela comunitaria que circula a través del "chisme" (Fasano, 2006). En este dinamismo cotidiano es donde muchas veces se institucionalizan una serie de categorías para pensar al otro, en este caso, al sujeto social joven, a partir de determinados parámetros "legítimos" fijados desde el mundo adulto que tienden a negativizarlo. De hecho, "en pueblo chico infierno grande" una de las cuestiones que más malestar generaba era la imposibilidad de resguardar la intimidad. El contrapunto de lo señalado, como aspecto negativizante y generador de malestares, es que la comunidad y su tejido de alta densidad discursiva hacía circular las 
problemáticas y necesidades posibilitando la movilización comunal para su resolución o tratamiento. Todo ello nos llevó a pensar que las fronteras entre el espacio público y el privado son sinuosas y complejas.

En este marco advertimos que en la resolución de las tensiones comunales intergeneracionales se ponen en juego diferentes formas de significación que dan como resultado prácticas que disminuyen las posibilidades y los destinos de los jóvenes ${ }^{1}$. La noción de destino es entendida como aquellas proyecciones que los sujetos sociales poseen en relación a las posibilidades brindadas por el Estado (Carli, 2005).

Poner el foco sobre la conflictividad social emergente en los sectores semirrurales desde un enfoque generacional tuvo como intención problematizar los diseños tradicionales y contemporáneos de las políticas sociales, que muchas veces perpetúan la inequidad existente en un mundo forjado por diferencias y asimetrías entre jóvenes y adultos.

Con el fin de contribuir a diseños integrales de políticas sociales, este artículo presenta una serie de aspectos relativos al conflicto en el espacio público y algunas claves a tener cuenta a partir del conocimiento de diversas experiencias y prácticas intergeneracionales de una comunidad semirrural.

\section{Villa Lucía $\underline{\underline{2}}$}

El trabajo de investigación-acción que desarrollamos en esta comuna se realizó en el marco de la Especialización en Abordaje Integral de Problemáticas Sociales en Ámbitos Comunitarios $\underline{3}$ dictada en la Universidad de Lanús, desde la cual se sistematizó la experiencia luego de concluirla.

$\mathrm{Al}$ ingresar en esta comuna se impone a la vista el Salón de Usos Múltiples (Propiedad de la Comuna) y una cancha de fútbol, la plaza del pueblo con algunos bancos y juegos para niños cuyo centro es una gruta pequeña. Producto de un clima árido se pueden ver los restos tupidos del monte autóctono, que sobrevivió a la tala de árboles, conformado por algarrobos, espinillos, quebrachos blancos, pastizales donde habitan pájaros, mulitas y serpientes venenosas como la víbora de coral, y distintas variedades de yarará. En el recorrido visual de Villa Lucía se observa una mixtura entre construcciones antiguas y nuevas, entre las que predominan las primeras en lo que sería el centro del poblado. Las zonas aledañas fueron desforestadas por causa del avance del monocultivo de la soja.

En esta comunidad ${ }^{4}$ semirrural, la cotidianeidad acontece en las doce manzanas que conforman la Comuna; en la tranquilidad de sus calles se puede observar la convivencia de prácticas tradicionales y nuevas, en relación con la producción doméstica. Así, nos encontramos con hornos de barro, hornos de carbón donde se realiza el arrope de tuna, la utilización de caballos para traslados, la cría de animales, etc., y al mismo tiempo muchos vecinos cuentan con todos los servicios, con el acceso y uso de las nuevas tecnologías, y la utilización de maquinaria y automóviles de última generación.

Los pobladores que ocupan su tiempo en trabajos estables son una minoría (vinculados a la agricultura, venta o servicios). Una franja significativa de la población está desocupada, sostenida en la trama socioeconómica por la presencia de políticas sociales y trabajos precarios. Además la movilidad hacia otras localidades cercanas se torna dificultosa por no poseer servicios de transporte público frecuente. Estas situaciones impactan significativamente en la posibilidad de inserción laboral de las familias y de los jóvenes sobre todo.

Si atendemos a esta caracterización, la comuna puede ser pensada como un espacio rururbano (García, Tulla i Pujol, y Valdovinos Perdices, 1995). Este concepto hace referencia a un continuo entre lo rural y lo urbano y fue desarrollado por antropólogos como Redfield o Lewis, referentes de la antropología urbana, quienes ponen de relieve la dicotomía que se expresa a través de la oposición entre estas dos categorías. Estos autores identifican respecto a este dinamismo seis categorías: el espacio urbano propiamente dicho, el espacio 
periurbano o áreas urbanas discontinuas, el espacio semiurbano (con alternancia de usos), el espacio semirrural urbanizado, el espacio rural dominado por la actividad agraria pero con algunas influencias urbanas como por ejemplo las derivadas de la descentralización industrial y el espacio rural "marginal".

En nuestro caso, el área de estudio comparte características del tercer y cuarto anillo, o sea, del espacio semirrural, donde se alternan una estructura anterior de hábitat rural con una nueva de residencias urbanas, donde aparecen áreas urbanas (no incluidas en el área metropolitana), pero donde también continúan siendo muy importantes las actividades agrícolas. Según los autores citados, el tercer y cuarto círculos representan el ejemplo más evidente de espacio rururbano donde se mixturan construcciones $\underline{5}$ antiguas y nuevas, aunque predominan las primeras en lo que sería el centro del poblado.

\section{Implicancias del modelo de desarrollo}

El modelo agro-extractivo-exportador ha incidido significativamente en las relaciones sociales, dejando a gran parte de la franja poblacional activa, laboralmente desocupada. Las fuentes laborales fueron extremadamente precarizadas, lo que generó escasas perspectivas de futuro, malestar y fuertes procesos migratorios a localidades o ciudades cercanas en busca de mejores oportunidades.

La actividad de ganadería y agricultura es la que fue ganando fuerza en el monte nativo que rodea a Villa Lucía, impidiendo la producción de carbón y leña en la zona, labor central en la economía regional. En los últimos 15 años se produjeron trasformaciones agrarias radicales que llevaron a la utilización de las tierras destinadas a la ganadería para el cultivo de soja principalmente. Esta situación incrementó un desarrollo económico inequitativo y desfavorable para la mayoría de la población, al restringirse el acceso a los recursos naturales y bienes materiales a partir de la pérdida de fuentes laborales. En este sentido, fue palpable en la dinámica cotidiana el impacto de los cambios descriptos, dado que tanto los jóvenes como los adultos expresan la necesidad de acceder a una fuente laboral.

Estas trasformaciones dieron lugar a cambios profundos en las configuraciones familiares que se alejaron de los modelos tradicionales y deseados dentro de las cosmovisiones de la dinámica comunal. Las familias del poblado mezclan características tradicionales y modernas con nuevas particularidades tales como: aumento del tiempo de la jornada laboral, necesidad de incorporar mujeres al mercado laboral, incremento de jefaturas femeninas, mayor dependencia económica de los jóvenes hacia la familia de origen.

Este "giro ecoterritorial” (Svampa, 2013) también produjo cambios en los trayectos de vida juvenil y se observa una discontinuidad en la trasmisión de saberes, oficios y valores culturales generacionales que dificultan, aún mas, la inserción sociolaboral en su pueblo de origen.

En síntesis, el modelo de desarrollo afectó la vida cotidiana de las familias en la comuna de Villa Lucía en general por el uso del suelo y la escasez de empleo, pero a la vez se observa que esto también afecta a las relaciones sociales particularmente en jóvenes y adultos. Mientras estos últimos responden a una operatoria institucional apegada a tradiciones y prácticas históricas, los jóvenes van construyendo modos de afrontar la vida vinculados más a la soledad y el desarraigo en un escenario que poco puede contemplar sus expectativas y cosmovisiones.

\section{Juventud(es) y políticas sociales}

En este trabajo se ha identificado una preeminencia por el punto de vista relacional para el análisis de lo juvenil. Perspectivas críticas de las ciencias sociales han demostrado los límites del pensamiento positivista a la hora de pensar la juventud, entre los que pueden citarse datos demográficos, pasajes de un estadio a otro, posiciones centradas en los cambios biológicos que delimitan la conducta, y otros. Pensamos las juventudes - 
en plural- como un giro conceptual que toma los aportes de la sociología, la antropología y la psicología, en el cual se sostiene la convicción de que nos referimos, no ya a una etapa de la vida, sino a una construcción social heterogénea, diversa y compleja, determinada también por las condiciones concretas de existencia (Duarte, 2012; Carreras, 2012; Chavez, 2010; Di Leo y Camarotti, 2013); esto demanda al menos dos puntualizaciones necesarias para su análisis: a) su estudio no puede escindirse del contexto socio-histórico, y b) la dimensión relacional es relevante para dar cuenta de cómo se configura el espectro subjetivo.

Pero además, esta perspectiva relacional nos acerca no solamente a los mundos juveniles, sino a las vinculaciones que los jóvenes establecen entre ellos y con otros, ya que sus características resultan de una tensión entre la categoría sociocultural asignada por la sociedad (conformada por un conjunto de instituciones “adultas”) y la actualización subjetiva a partir de la interiorización diferenciada de los esquemas de la cultura vigente (Reguillo, 2000a). En definitiva, lo que nos ayuda a visualizar la idea de juventudes es que cuando estamos ante un actor social joven estamos también ante la presencia de experiencias tan heterogéneas y particulares como frente a una multiplicidad de características sociales y materiales.

Ahora bien, podemos decir sin temor a equivocarnos que las políticas sociales destinadas a jóvenes son escasas y no contemplan integralmente a la categoría juventudes que estamos discutiendo. Sin embargo, diferentes programas en la esfera educacional y/o laboral han buscado que los jóvenes completaran sus estudios o ingresaran a un empleo. Por ejemplo, el Plan Fines ${ }^{6}$ o Jóvenes con Más y Mejor Trabajo ${ }^{7}$ dan cuenta de la categoría discutida en párrafos anteriores sobre las juventudes. No obstante, las distancias entre su diseño y su implementación muchas veces socavan el fundamento universalista de la política.

Balardini (2002) afirma que el diseño de las políticas de juventud se vincula firmemente con el concepto de juventud que opere de base, ya que implica un posicionamiento a nivel ontológico (sujeto y realidad). Entonces, distintos modelos de articulación con los jóvenes van a fortalecer la construcción de distintos sujetos -y bien diferentes- según este modelo sea «para», «por», «con», o «desde» la juventud.

Según un estudio realizado por Unicef (s/f), la Argentina tiene una importante cobertura que asegura el acceso a la escolaridad a toda la población, pero buena parte de los jóvenes no terminan cursos obligatorios y experimentan situaciones de desventaja que conllevan a dejar la escuela. Los datos publicados por DINIECE (Dirección Nacional de Evaluación de la Calidad Educativa) muestran que, entre 2009-2010, un 9,3 \% de los alumnos desertaron anualmente del ciclo básico de la escuela secundaria, y un $15.5 \%$ hizo lo propio en el ciclo de orientaciones. Esos índices bajan a 8,2 \% en el ciclo básico y 13,9 \% en el ciclo de orientaciones en la provincia de Córdoba. Muchos educadores coinciden en que a pesar de las inversiones realizadas, el sistema educativo no termina de garantizar el acceso para su terminalidad.

El desempleo juvenil es otro problema que América Latina enfrenta desde hace años. Ocho millones de jóvenes de entre 15 y 24 años no consiguen empleo; además, otros 27 millones de ellos trabajan en condiciones de informalidad, así lo planteó la Organización Mundial del Trabajo durante el 2015.

El promedio regional de desempleo juvenil en Latinoamérica en el 2014 era de 14,23 \%, sin embargo, Argentina fue uno de los países que logró reducir el desempleo juvenil (en un 7,5 \%). Según el Grupo de Estudios de Economía Nacional y Popular (Greenap), en 2006 había un 25,2 \% y en 2014 un 17,7 \%, es decir, que Argentina mejoró radicalmente su situación (por sus políticas activas de promoción del empleo) y, por otra parte, los datos mostraron también que el desempleo juvenil se debe en gran medida a la crisis económica de todo el mundo y no una a cuestión estrictamente particular de este país. (Datos consultados en Universia fundación, 2015)

Por lo que, ante estas cifras, la política pública debe solidificarse en un continuo temporal, es decir, no pueden ser puntuales y esporádicas sino que su implementación debe tener integralidad, continuidad y permanencia (Saintout, 2007), lo cual trae aparejado un enorme desafío de la gestión política de la misma 
como también de la dinámica de formulación e implementación.

\section{Conflicto y Generación}

La revisión para explorar la noción de conflicto partió desde el enfoque psicológico (Freud, 1901; Bleger, 2003), pasó por lecturas enmarcadas en lo social comunitario (Nató, Querejazu, y Carbajal, 2006; González Calleja, 2004), y arribó a perspectivas sociológicas (Coser, 1970; Scribano, 2007; Murillo, 2008; Vergara Arias, 2009). En este recorrido, notamos como puntos comunes respecto a la noción de conflicto la presencia de intereses contrapuestos y de motivaciones incompatibles entre actores (individuales o colectivos) en un contexto de producción que permite su manifestación. A su vez, el conflicto desde todas estas perspectivas reviste una cualidad positiva, sea como tramitador de las situaciones interpersonales-comunitarias, o bien como motorizador del cambio social fruto de la puesta en juego de la disputa que involucra a las partes. En todos los casos, afrontar es mejor que evitar.

Trazada esta idea básica de conflicto, avanzaremos en la comprensión de los vínculos entre jóvenes y adultos en la dimensión intergeneracional, entendida ésta como una categoría relacional que implica centrar la mirada en las interacciones entre generaciones.

Por lo tanto, es justamente la idea de generación la que requiere precisión. El proceso de lectura de autores $\underline{8}$ que abordan la dimensión generacional nos llevó a visualizar que la idea de generación está envuelta en un campo conceptual bastante paradojal, ya que esta categoría abarca desde una serie de atributos aplicables a todos los nacidos en determinados años (generación de los 60, 90 o “x”, "z”, etc.) hasta una construcción tan singular y tan relativa a las formas de agregación que se asemeja a la idea de identidad, y que a su vez plantea rasgos que delimitan a la generación (generación multimedia, replicante, indignada, @, etc.).

Más allá de este campo paradojal, nos parece necesario proponer, al menos provisoriamente, una noción que circunscriba y nos posicione respecto a lo intergeneracional: como un dinamismo relacional entre aquellos grupos que, además de ser contemporáneos a una historia social, comparten una serie de "enlaces" (experiencias subjetivantes) que les permiten identificarse dentro de una generación y no otra. Entendemos que las generaciones son experiencias subjetivas vinculadas a los contextos sociales y a los trayectos que los grupos humanos despliegan en el movimiento de reproducción/excepción que demarca la vida cotidiana.

Esto nos permite comprender el conflicto generacional como una dinámica que se desarrolla desde el plano interpersonal al plano social y viceversa; una dinámica en la que los intereses contrapuestos y el contexto de producción son consecuencias de una realidad asimétrica que se expresa tanto en los vínculos en los que predominan las relaciones adultocéntricas $\underline{\underline{9}}$ como en la relación que los colectivos humanos entablan con el Estado, las instituciones, la comunidad y la sociedad en general.

En este sentido, podemos decir que el conflicto generacional es un proceso "natural" dentro de los modos de reproducción social actuales que se vincula con las "configuraciones culturales” 10 que unos y otros ponen a debatir en sus encuentros. Sin embargo, frente a los escenarios sociohistóricos caracterizados por un modelo de desarrollo que produce desempleo, la ausencia de políticas sociales formuladas desde o para los jóvenes y la ruptura de la trasmisión intergeneracional de saberes y oficios hacen que la condición "natural" pase a ser un problema social que obstaculiza las proyecciones y destinos de las vidas juveniles.

De este modo, las relaciones generacionales ponen de manifiesto disputas de poder que se vinculan con las propias configuraciones culturales que posicionan a los jóvenes en una generación y no en otra; además, las mismas pueden entrar en conflicto. Sobre la base de nuestra experiencia en Villa Lucía podemos decir que, si bien el conflicto generacional se produce por la resistencia que los jóvenes presentan ante la asimetría de la matriz adultocrática, también advertimos que esa matriz ingresa en conflicto con otra matriz joven, con otra 
configuración cultural que no siempre implica asimetría. Es decir, las juventudes de Villa Lucía ostentan e imponen $\underline{11}$ su matriz en determinados ámbitos que los posicionan asimétricamente respecto de los adultos, por ejemplo, en el ámbito de los consumos, de las tecnologías, de las violencias, de la apropiación de determinados espacios públicos.

A su vez, reconocimos que los adultos muestran tensión ante las novedades que traen aparejadas las nuevas generaciones. Tensión que puede devenir en conflicto o no, pero que en perspectiva relacional implica novedad, cambio e innovación en las generaciones adultas. Sus repertorios también comienzan a mostrar modificaciones y nuevas configuraciones al igual que las novedades que ingresan los jóvenes en sus modos de andar la vida. Sin embargo, estas prácticas no son suficientes para afrontar lo que el conflicto generacional implica en este momento sociohistórico.

\section{Actores, Escenarios y Conflictividad: anudamientos y desencuentros generacionales}

A continuación caracterizaremos los actores y escenarios de la trama generacional de Villa Lucía que, durante el periodo de práctica (2011-2012), nos brindaron mayores insumos en la tarea de conocer los modos de relacionamiento conflictivos intergeneracionales en el espacio público:

1) La gestión comunal es un actor central en la dinámica comunitaria a través de acciones tendientes a la inclusión social y el desarrollo local; implica la formulación, gestión de acciones tendientes a mejorar los servicios de salud, educación, vivienda y saneamiento de la comuna que se representa, siempre con un objetivo de construcción de legitimidad política en el territorio. Gracias al contacto cotidiano en la acción con los efectores de la gestión comunal pudimos reconocer las siguientes características:

a. Centralidad en el eje político partidario: el enérgico trabajo en gestión de recursos tanto económicos como humanos, vinculados a las necesidades de la población y a los derechos inalienables de las personas, se anuda al proyecto de política social a nivel nacional y a sus lineamientos de territorialidad e integralidad.

b. Omnipresencia de la jefa comunal: se hace referencia su presencia en una amplia variedad de esferas de la vida del pueblo que trascienden su función como jefa comunal. Figura posible por la relación que se establece entre ella y los recursos de movilidad y económicos, necesarios para los sectores más postergados. De esta manera, todo lo que ocurre diariamente o acontece está mediado por la presencia de la jefa comunal que opera como un actor regulador de la vida social/moral y política. Este liderazgo se ha desarrollado con cierto autoritarismo y desde una mirada caritativa en la resolución de los problemas comunales. De este modo, las políticas que desde el Ministerio de Desarrollo Social de la Nación se destinaban a las comunas eran rápidamente trasferidas a la población como parte de la gestión comunal que escogía brindar una vivienda, una ayuda urgente, o una pensión según la relación que éstas tenían con la Jefa Comunal. Aparecía más la idea de "favor" que de derecho adquirido. Así, quienes recibían asistencia de parte del Estado eran vistos como beneficiarios, es decir, como objetos de la política social.

2) El Centro de Integración Comunitario (CIC) y la Mesa de Gestión Local (MGL) como políticas sociales, cogestionadas por la Comuna y Gobierno de la Nación, constituyen parte de un modelo de gestión pública basado en la promoción social que implica la integración y coordinación de políticas de atención primaria de salud y desarrollo social en un ámbito físico común de escala municipal.

Estos espacios funcionan como un lugar de encuentro entre la sociedad civil y el gobierno local, donde los grupos intervinientes participan en actividades y/o proyectos que les permiten mejorar las condiciones de vida de los pobladores. A su vez, este espacio y modalidad de participación posee el reconocimiento de los actores comunitarios e instituciones como un espacio común, público y con una infraestructura que permite la articulación, gestión e implementación de los proyectos con otros niveles de gobierno. 
Del análisis de las actas de las reuniones de MGL podría decirse que de las siete reuniones asentadas en actas desde julio del 2009 hasta abril de 2012, en todas las reuniones se encontraban presentes representantes de áreas del Estado que venían a vehiculizar proyectos o monitorear la implementación. Como dato significativo se observa que el $90 \%$ del contenido de los temarios refiere a elementos materiales (construcción, mejoras, ampliaciones, núcleos húmedos, obras, etc.), y el $10 \%$ restante se vincula a problemáticas sociales de la comunidad, la planificación y organización de eventos y gestión de proyectos.

Este análisis de las actas deja a las claras que la MGL es un motor dinamizador que podría caracterizarse desde el adentro (Sánchez Vidal, 2007b) de las necesidades y demandas de los pobladores y desde arriba, ya que no solamente hay atravesamientos en la gestión que se alinean con las directrices del MDS (Ministerio de Desarrollo Social), sino también que la gestión va un paso delante de los procesos de participación y organización comunitaria. Dicha dinámica trae aparejada, por un lado, una fuerte movilidad comunal por la implementación de proyectos que modifican las condiciones de vida de los pobladores y del pueblo y, por otro, sitúa a los pobladores participantes de las acciones que se vinculan con sus necesidades, demandas y derechos como meros espectadores y receptores.

Hasta aquí presentamos algunas dinámicas adultas en el proceso de investigación-acción, en las que la mayoría señala a los jóvenes como la población que más preocupación presenta por no contar con actividades y porque se dan dificultades para contenerlos. A continuación damos cuenta de las miradas de los jóvenes de la comuna de Villa Lucía a partir de la relación que éstos entablan con los mundos adultos (instituciones, políticas sociales, gestión, etc.).

3) Los jóvenes de Villa Lucía con los que se realizó la experiencia fueron 12, en su mayoría involucrados en Ciclo Básico Unificado (CBU) o Ciclo de Especialización (CE). A partir del acompañamiento que realizamos en los talleres de educación sexual efectuados dentro del espacio curricular se proyectaron una serie de espacios extraescolares que permitieron la inclusión de otros temas, otros jóvenes no escolarizados y otras acciones.

El proceso de investigación permitió el encuentro con un grupo de jóvenes varones y mujeres entre 13 y 20 años, heterogéneo tanto en género como en condición sociocultural. Cada encuentro con ellos fue en experiencia muy particular por sus formas de comunicar, sus tiempos, sus formas de interactuar.

En los tránsitos y las interacciones con los adultos notamos que los jóvenes -como grupo social- cuentan con un descrédito significativo en lo que respecta a sus intereses y necesidades (culturales, recreativas, sociales); es decir, que sus proyectos, deseos y actividades -siempre y cuando no estén vinculadas a la educación, religión o el trabajo- son puestas en tensión por los adultos, sean estos familiares, educadores o referentes de las organizaciones de la comunidad.

Para los jóvenes, el grupo de pares es el espacio privilegiado de socialización, conforma parte sustancial de la "familia afectiva", la comunidad con la que crean lazos que mantienen y aportan sentido a sus vidas y proyectos. En algunos casos, el grupo juvenil se convierte en el vehículo de expresión social, ya sea por medio de lo contracultural, del deporte, de lo político, o de algún servicio comunitario.

Respecto al uso del tiempo libre plantean que "después (de la escuela) no hacemos nada..., no hay nada para hacer..., nos juntamos en la casa de alguno, pero estamos ahí..., nos quedamos viendo la novela” (Notas de campo; 16-06-11). En la noche se visualiza una situación similar, ya que solamente se juntan cuando hay algún cumpleaños, manifiestan que no hay nada para hacer. Los espacios nocturnos son solo para los adultos, no existen espacios de encuentro que los acojan. Los jóvenes ponen mucho énfasis en actividades recreativas nocturnas, mientras los adultos ponen en tensión esas propuestas. Los adultos tienden a pensar propuestas para los jóvenes vinculadas al deporte y la religión. 
Es importante subrayar que los adultos vinculan fuertemente el ocio forzado al consumo de sustancias, sin embargo, los jóvenes contactados no manifiestan lo mismo. Vale aquí decir que en Villa Lucía uno de los problemas identificados fue el consumo de alcohol por parte de los adultos. El conocer estos aspectos disonantes es lo que permite entender parte de la conflictiva situación que luego se actualiza en el espacio público.

Veamos en este sentido cómo los registros de campo de una actividad grupal de los jóvenes muestran modos de representación respecto a:

¿Qué es ser adulto?, “tener trabajo..., una familia..., hijos... Ser responsable..., saber más de la vida..., tener tu propia plata..., poder hacer lo que quieras”. ¿Y ser joven?, “estar dando vueltas..., jugar..., salir..., usar la compu..., ir a la escuela..., estudiar..., preparase para salir a estudiar o trabajar..., salgo con mis amigos..., vamos a la plaza..., tomamos algo..., vamos a fiestas de cumpleaños..., salimos a Tránsito..., jugamos al fútbol..., buscamos a las chicas..., jugamos en la compu o la play..., estudio cuando tengo tiempo..., trabajo en mi casa..., ayudo a mi mamá, cuido a los chicos..., salgo con mis amigas..., andamos en bici..., vamos a la plaza a charlar..., jugamos al fútbol con los chicos..., estudiamos y vamos a las escuela” (Notas de campo; 28-07-11).

La idea de que la educación secundaria no tiene tanto que ver con el futuro laboral fue una relación constante en los discursos juveniles. Sin embargo, los participantes valoran significativamente este espacio como espacio social y muchos proyectan continuar sus estudios, aunque la mayoría de los jóvenes no accede a estudios terciarios por las dificultades económicas.

Otro foco de atención fue la relación con las nuevas tecnologías. Puede decirse que muestran gran motivación para su uso, y aunque no cuentan con redes de conexión a internet, viajan $30 \mathrm{Km}$ para acceder al cyber. También debemos agregar que la señal de celular es muy débil, lo que impide la utilización de este medio para acceder a las redes sociales. Se visualizan fuertes tensiones en los jóvenes en relación con el acceso a las tecnologías y acceso a los bienes de consumo.

Los jóvenes mostraron una dinámica propia, propositiva, con fuerte tendencia a la acción y con capacidad organizativa en relación con las propuestas que ellos enuncian. A su vez, presentan miradas alternativas en los modos de hacer adultos (fiestas, eventos culturales, campeonatos, prácticas religiosas, etc.). Sin embargo, ellos no participan de espacios intergeneracionales de disputa y construcción, como podría ser la Mesa de Gestión Local. En este sentido, son los adultos vinculados a ellos quienes trasmiten sus inquietudes y deseos (docentes, equipo de salud, familiares). Es decir, no presentan sus modos de construcción y disputas en estos espacios.

Visualizamos que la matriz asistencial clientelar ya planteada posee un peso decisivo en las prácticas adultoinstitucionales, en cambio, en los jóvenes advertimos que no poseen tan internalizada esta dinámica vincular y comunitaria, por lo tanto, y como pudo verse en el encuentro con ellos, presentan miradas alternativas de las vivencias y relatos adultos. Así, por ejemplo, para los jóvenes, el CIC o las políticas sociales no están directamente relacionadas con la jefa comunal, como insisten las voces adultas, para ellos el CIC es un espacio más que de hecho ni siquiera genera disputa. Correlato de ello es que los jóvenes no participan de instancias organizativas propuestas por los adultos; no reciben sus propuestas favorablemente, son productores de sus propias acciones y destinatarios de la política social.

\section{Políticas sociales situadas: entre el diseño y la implementación}

Nos interesa complementar la discusión desde la perspectiva de las políticas sociales centradas en la noción de promoción social. Entendemos a esta noción como una tendencia de la política social que procura 
“impulsar la participación activa de los sujetos para dar respuesta a las problemáticas de la comunidad, recuperando las capacidades instaladas a partir de su propia experiencia y vinculando lo estrictamente ‘social’ sin escindirse de lo económico” (Kirchner, 2007).

Señalamos tres aspectos significativos que reflejan distancias entre la formulación a nivel nacional y la implementación (cogestión comuna, provincia y nación) a nivel local que tensionan la noción de promoción social, a saber:

A) La presencia del Estado Nacional a través de políticas sociales permite sostener el entramado social de la localidad, principalmente en aspectos vinculados a la salud, educación, cultura y trabajo. Sin embargo, acceder a las políticas sociales suele ser para las comunas un interjuego clientelar agudizado en los momentos electorales y profundamente naturalizado en los distintos actores sociales.

B) Las demandas y necesidades de los pobladores son tramitadas y “resueltas” por la gestión comunal, lo cual sitúa a la comunidad como mera espectadora de los procesos de cambio que promueven el mejoramiento de su calidad de vida. La Mesa de Gestión Local “a demanda” es un correlato de este dinamismo.

C) La desarticulación y superposición de recursos y programas sociales de organismos (públicos y privados) que realizan diagnósticos y propuestas de acción social sin concluirlas producen desgaste en la participación, desánimo y pérdida de credibilidad sobre la posibilidad de cambio y transformación.

Si bien los puntos arriba marcados dan cuenta de situaciones que obstaculizaron los procesos de participación comunitaria y cooperación social, debemos decir que en Villa Lucía la implementación de las políticas sociales ha repercutido en el fortalecimiento de los procesos organizativos de la propia comunidad y ha convocado a la participación popular fortaleciendo tanto la ciudadanía como los capitales sociales y culturales propios de esta comunidad.

Se perciben entonces valoraciones contrapuestas respecto a la implementación de las políticas sociales. Porque si bien se puede hablar de una cierta “distorsión” de la política social (MGL a demanda, uso clientelar-asistencial, etc.) ello no implica la invalidez de los avances generados por ella. Lo que se desprende de esta ambivalencia es un abismo entre la formulación y la implementación de las políticas sociales cuyo efecto paradójico es promover aquello que quieren mitigar. Por ejemplo, el asistencialismo, la dependencia, las políticas sociales focalizadas son propiciadas por los equipos técnicos y la gestión política para condicionar el voto. Advertimos que cuando se funden los objetivos de la política partidaria con los de la política social ésta queda pervertida y subsumida en la otra. Creemos que subsanar estos problemas requiere de construir la política social del territorio comunal hacia el espacio estatal. Es decir, en sentido inverso a lo que pudimos ver en el territorio.

Por otra parte, para disminuir las distancias entre la formulación y la implementación también es necesaria la participación real de los pobladores en articulaciones en las que primen los lazos solidarios por sobre los intereses particulares de la gestión política, lo cual permitiría, al mismo tiempo, la optimización del uso de los recursos y la sustentabilidad de las acciones que se emprendan.

\section{Hallazgos}

Lo que pudimos conocer de la gestión política en los espacios articulación (MGL y CIC) y con los jóvenes nos lleva a plantear los siguientes aspectos relativos al conflicto en el espacio público a tener en cuenta para el diseño de políticas sociales:

a) Consumo de sustancias: es una temática señalada principalmente por los adultos como un problema de la 
franja juvenil que acontece en el espacio público. En este espacio ambas generaciones tensionan lo diferente sin reconocer sus propias prácticas. Los jóvenes plantean el consumo de alcohol de los adultos como un problema pero también como una costumbre a la que ellos pueden dar otros sentidos. Los adultos plantean el consumo de los jóvenes como un problema asociado al ocio; es decir, el problema es el consumo asociado con "el estar en Villa Lucía" sin seguir el mandato adulto. Por ello, el conflicto acontece cuando los jóvenes "toman algo en la plaza o la esquina”. No se tematiza de la misma forma el consumo con los jóvenes que trabajan. Es importante señalar que se registraron distintas situaciones de conflicto extremo en las que el consumo de alcohol fue uno de los promotores (fiestas, campeonatos de fútbol, fiestas patrias, votaciones).

b) La plaza, calle, la pirca. Se vincula con el punto anterior, ya que la disputa tiene que ver con prácticas visibles que los adultos señalan como fuera de lugar; a su vez, los jóvenes plantean que no hay espacios para hacer las cosas de ellos, el reunirse a la siesta en la pirca, el tomar algo en la plaza, el andar por las calle, las peleas entre ellos, los romances, la violencia de pareja o sus juegos pueden ser señalados como algo que irrumpe, que es moralmente sancionable o producto del exceso de tiempo libre. Al respecto se señala que estas formas de estar de los jóvenes son en algún punto avaladas por las instituciones. Estas lógicas se tensan pero no ingresan en diálogo.

c) Convivencia en los espacios institucionales. Aquí se hace referencia a los conflictos que acontecen en la institución educativa entre educadores y estudiantes, sean éstos por conducta, falta de motivación o dificultades en el proceso de aprendizaje. Se ponen de manifiesto en la esfera de la educación, el trabajo y la cultura diferencias sustanciales entre los mandatos adultos, los deseos y necesidades juveniles y las posibilidades de realización.

d) Espacios de participación. Se reconoce que los jóvenes son un grupo con propuestas y capacidad de organizarse. A su vez desde los adultos se ofrecen instancias de participación para recibir esas propuestas, sin embargo, las mismas no son tenidas en cuenta si no responden a los intereses de los adultos o de la gestión. Los adultos son permisivos mientras se sostengan sus mandatos.

\section{Consideraciones finales}

Esta experiencia nos ha permitido poner el foco sobre una temática diferente a las que tradicionalmente han abordado las políticas sociales (trabajo, educación, familia, deporte, etc.). El conflicto generacional -como un eje trasversal- se podría concebir como una dimensión relevante a tener en cuenta, tanto en el diseño como en la implementación de las políticas sociales. Presentaremos a continuación dos claves analíticas que intentan contribuir con el diseño de políticas sociales (desde lo situado) y mejorar los modos de interacción generacional entre jóvenes y adultos para promover con ello procesos tendientes a regular la conflictividad analizada a lo largo del artículo.

En primer lugar, nos parece relevante conocer cuál es la disputa de sentido que conforma el núcleo de los conflictos que tensan las relaciones entre los sujetos sociales implicados. Sentidos que implican significaciones diferenciales respecto de las necesidades, los proyectos, las motivaciones y deseos; sentidos que son construidos en los propios trayectos históricos de los protagonistas y que de alguna manera los posicionan dentro de una generación y no de otra.

Advertimos que en el juego de poderes que se libra entre generaciones se impone una matriz adultocéntrica, performativa de las relaciones cotidianas, que no solamente pesa sobre los trayectos juveniles, sino que ellos mismos la reproducen. Ello se manifiesta, tanto a nivel institucional (Comuna, escuelas, centro de salud, etc) como organizacional (cooperativas, mesa de gestión, etc.). Estas disputas de sentido, que a veces devienen en conflicto generacional, impregnan la vida cotidiana, configuran los modos de relacionarse entre unos y otros, y muestran nuevas y necesarias coordenadas para la búsqueda de formas de interacción comunitaria más 
armónicas.

En segundo lugar, en el proceso de investigación identificamos la negativización del relato comunitario, expresado en "el chisme". Muchos de los conflictos intergeneracionales son amplificados con un sesgo negativo y se instalan en el espacio público porque el mensaje mediatizado tiene la capacidad de atravesar las barreras de lo privado, para ingresar preponderantemente en los espacios del "lazo colectivo". Esto provoca una confusión en los límites entre lo público y lo privado. Así, el espacio privado posee cierta relatividad, ya que forma parte de la novela comunitaria que circula. El hecho de que la urdimbre social del pueblo tenga alta densidad y múltiples conexiones produce malestar, dado que imposibilita el resguardo de la intimidad. Lo que circula tiende a situar a determinados sectores-actores en evidencia, y amplifica aspectos negativos (de las familias pobres, de los jóvenes) que tienden a marcar diferencias. Es justamente en ese cotidiano donde se institucionalizan una serie de categorías desde el mundo adulto hacia los jóvenes en particular. Se cristalizan categorías de reconocimiento o desvalor.

Consideramos que lo señalado en la orientación de las políticas sociales podría incidir en las condiciones objetivas y subjetivas de una comunidad.

El proceso de praxis nos posibilitó reconocer como:

a) Los aspectos socioeconómicos dejaron a un pueblo cercado por la soja, lo cual rompió las economías locales y la trasmisión de los oficios de generación en generación.

b) La política de gestión y las políticas sociales regulan, matizan o favorecen un tipo de conflicto comunitario -motivado por el encuentro con lo diferente- funcional a los centros de poder local (Comuna, instituciones, adultos, etc.).

Esto lleva a pensar en la necesidad de tener en cuenta vectores trasversales -como lo es el conflicto que se actualiza entre las generaciones diferentes- para evitar políticas que intensifiquen la tensión entre generaciones. Esto presenta el desafío permanente de reinventar las políticas sociales para continuar relaciones más igualitarias en la comunidad que brinden mejores oportunidades tanto para los jóvenes del sector como para las otras generaciones.

Por último, resulta adecuado reafirmar que este análisis propuesto corresponde al último gobierno a cargo de Cristina Fernández de Kirchner en el cual la política social constituyó un eje gubernamental central, caracterizado por la promoción social y el desarrollo autogestivo de los sectores más desfavorecidos a partir de una gestión asociada, es decir, una política social que implicó niveles de asociatividad entre Nación, provincia y municipio. Con la llegada del nuevo gobierno lo mencionado parece imposible, y sostenemos que la política social hoy se ha convertido en una práctica subsidiaria de los sectores nuevamente empobrecidos por un modelo de desarrollo de país excluyente que privilegia a los grupos concentrados de la economía.

\section{Notas}

1 El uso del genérico en masculino no implica ningún sesgo sexista en el uso del lenguaje. Se lo adopta a los fines de facilitar la lectura del artículo.

$\underline{2}$ Los nombres de personas y lugares han sido cambiados para proteger la identidad de los protagonistas y resguardar información específica del territorio en cuestión.

$\underline{3}$ En convenio con el Ministerio de Desarrollo Social de la Nación. La práctica profesional y la sistematización asentaron, en su mayoría, en los Centros de Integración Comunitaria.

4 Se entenderá por comunidad, según los planteos de Ignacio Lewkowicz (1998), a aquella comunidad 
efectiva que no es una entidad dada, definible en términos de "ser" con tales o cuales propiedades a priori. La comunidad efectiva es un hacer -y sobre todo un hacer-se-. Es hacerse en posición subjetiva; es hacerse de una posición subjetiva. La comunidad efectiva nunca es "la" comunidad, sino siempre "esta" comunidad.

$\underline{5}$ Los ranchos y casas precarias han sido erradicados casi en su totalidad por el Programa Mejoramiento Habitacional e Infraestructura Básica, dependiente de Ministerio de Planificación Federal, Inversión Pública y Servicios, el cual busca fomentar el desarrollo y el mejoramiento de las condiciones del hábitat, la vivienda y la infraestructura social de los hogares con NBI (Necesidades Básicas Insatisfechas) y los grupos vulnerables en situación de emergencia, riesgo o marginalidad, ubicados en pequeñas poblaciones, parajes, áreas rurales o comunidades aborígenes.

6 El Plan Fines es una política educativa del Ministerio de Educación de la Nación iniciada entre 2008/2009 dirigida a todos los jóvenes de 18 a 25 años que no hayan finalizado sus estudios primarios y/o secundarios. Su objetivo es ofrecer un plan específico para la terminalidad de dichos estudios.

Z El Programa busca generar oportunidades de inclusión social y laboral de los jóvenes, a través de acciones integradas, que les permitan construir el perfil profesional en el cual deseen desempeñarse, finalizar su escolaridad obligatoria, realizar experiencias de formación y prácticas calificantes en ambientes de trabajo, iniciar una actividad productiva de manera independiente 0 insertarse en un empleo. http://www.educ.ar/sitios/educar/recursos/ver?id=111478\&referente=

8_Duarte, 2001, 2002 y 2006; Ghiardo, 2004; González Calleja, 2004; Manzano, 2010; Reguillo, 2012; Lewkowicz, 2003; Mannheim, 1961; Alvarado y Vommaro, 2010; Feixa, 2000; Vommaro, 2013, entre otros.

9 "Sitúa lo adulto como punto de referencia para el mundo juvenil, en función del deber ser, de lo que debe hacerse para ser considerado en la sociedad (madurez, responsabilidad, integración al mercado de consumo y producción, reproducción de la familia, participación cívica.)” (Duarte, 2001, p. 67).

10 Noción entendida como un "espacio en el cual hay tramas simbólicas compartidas, hay horizontes de posibilidad, hay desigualdades de poder, hay historicidad. Se trata de una noción útil contra la idea objetivista de que hay culturas esenciales, y contra el postulado posmoderno de que las culturas son fragmentos diversos que solo los investigadores ficcionalizan como totalidades". "La noción de configuración cultural busca enfatizar tanto la heterogeneidad como el hecho de que ésta se encuentra, en cada contexto, articulada de un modo específico” (Grimson, 2011, p.28).

11 Esta manera de poner en juego su propio trayecto nos hizo pensar en la idea de Revancha presentada por Reguillo (2000b). Se refiere a este concepto como prácticas, usos de micropoderes donde los distintos actores sociales buscan subvertir el orden programado afirmando su existencia, imprimiendo su huella, su autoría.

\section{Bibliografía}

Alvarado, S. V., Y Vommaro, P. (2010). Jóvenes, cultura y política en América Latina: algunos trayectos de sus relaciones, experiencias y lecturas (1960-2000). Buenos Aires: CLACSO

Balardini, S. (2000). De los jóvenes, la juventud y las políticas de juventud. Última década, 8(13), 11-24. Recuperado de http://www.scielo.cl/scielo.php?script=sci arttext\&pid=S0718

Bleger, J. (2003). Psicología de la conducta. México: Paidós.

Carli, S. (2005). Infancia, cultura y educación en las décadas del 80 y 90 en Argentina. Documento de trabajo $\mathrm{n}^{\circ}$ 15. Serie "Documento de trabajo". Escuela de Educación. Universidad de San Andrés. Buenos Aires. Carreras, R. (2012). Juventudes, medios y conflictividad. Revista Interferencia, Vol. O(2), 33- 37 
Chaves, M. (2010). Jóvenes, territorios y complicidades. Una antropología de la juventud urbana. Buenos Aires: Espacio.

Chávez Méndez, G. Y Daza Sanabria, J. C. (2003). Reflexión metodológica sobre la aplicación concreta de la Investigación Acción Participativa (IAP) en contextos rurales del estado de Colima. Estudios sobre las Culturas Contemporáneas, Junio, 115-146.

Corea, C., Lewkowicz, I., y de La Aldea, E. (1998). La comunidad, entre lo público y lo privado. Revista Campo Grupal Año1, 2. [En línea]. http://www.elenadelaaldea.com.ar/1998/09/la-comunidad-entre-loprivado-y-lopublico/

Coser, L. (1970). Nuevos aportes a la teoría del conflicto Social. Buenos Aires: Amorrortu.

Das, V., Y Poole, D. (2008). El Estado y sus márgenes. Etnografías comparadas. Cuadernos de Antropología Social, 27, 19-52.

Delgado, M. (1999). El animal público. Barcelona: Anagrama

Di Leo, P., Y Camarotti, A. (2013). Quiero escribir mi historia. Vidas de jóvenes de barrios populares. Buenos Aires: Biblos.

Duarte Quapper, C. (2012). Sociedades adultocéntricas: sobre sus orígenes y reproducción. Revista Última década, 36, 99-125.

Fals Borda, O., y Rodríguez Brandao, C. (1986). Investigación participativa. Montevideo: De la Banda oriental.

Fasano, P. (2006). De boca en boca: el chisme de la trama social de la pobreza. Posadas: Antropofagia.

Feixa, C. (2000). Generación @ La Juventud en la Era Digital. Nómadas (Col), Octubre, 75-91.

Freud, S. (1901). Psicopatología de la vida cotidiana. Obras completas (Vol. VI). Buenos Aires: Amorrortu.

García Ramón, M. D., Tulla I Pujol, A. F Y Valdovinos Perdices, N. (1995). Geografía Rural. España: Síntesis.

Ghiardo, F. (2004). Generaciones y Juventud: una relectura desde Manheim y Ortega y Gasset. Última década, 12(20), 11-46. Recuperado de http://www.scielo.cl/scielo.php?script=sci arttext\&pid=S0718

González Calleja, E. (2004). Las jóvenes generaciones contemporáneas. Evolución de los modos conflictivos de participación política. Mélanges de la Casa de Velásquez. Jóvenes en la historia, 34, 217-242.

Grimson, A. (2011). Los límites de la cultura, crítica de las teorías de la identidad. Buenos Aires: Siglo XXI.

Guber, R. (2001). La etnografía, método, campo y reflexividad. Bogotá: Norma.

Hecht, A. C., Martínez, G. J. y Cúneo, P. (2008). Infancia toba y mundo natural: De la atención del malestar físico a las pautas de socialización infantil. Acta Americana, 16(1), 81-106.

Informe UNICEF (s/f) Informe nacional. Las oportunidades educativas en argentina (1998- 2010).

Kirchner, A. (2007). Módulo de Políticas Sociales, Carrera de Especialización en Abordaje integral de problemáticas sociales. Ministerio de Desarrollo Social - UNLa.

Mannheim, K. (1993 [1928]). El problema de las generaciones. Revista Española de investigación sociológica, 62, 193-242.

Manzano, V. (2010). Juventud y modernización sociocultural en la Argentina de los sesenta. Desarrollo 
Económico, 363-390.

Murillo, S. (2008). El conflicto social en Michel Foucault. Conflicto Social, 1(01),156-180.

Nató, A. M., Querejazu, M. G. R., y Carbajal, L. M. (2006). Mediación comunitaria: conflictos en el escenario social urbano: conflictos en la comunidad, conflictos públicos, conflictos interculturales, enfoques y abordajes. Buenos Aires: Editorial Universidad.

Reguillo, R. (2000a). Emergencias de culturas juveniles. Estrategias del desencanto. México: Norma.

Reguillo, R. (2000b). La clandestina centralidad de la vida cotidiana. En LINDON, A. (Coord.). La vida cotidiana y su espacio-temporalidad (pp. 77-97). Barcelona: Anthropos-CRIM-El Colegio Mexiquense.

Reguillo, R. (2012): Navegaciones errantes. De músicas, jóvenes y redes: de Facebook a Youtube y viceversa. Comunicación y sociedad, 18, 135-171.

Saintout, F. J. (2007). Jóvenes e incertidumbres: percepciones de un tiempo de cambios. Familia, escuela, trabajo y política (Tesis doctoral). FLACSO. Argentina.

Sánchez Vidal, A. (2007a). Manual de Psicología Comunitaria. Madrid: Pirámide.

Sánchez Vidal, A. (2007b). Intervención comunitaria: concepto, proceso y panorámica. En A. Sánchez Vidal (Comp.). Psicología Comunitaria. Bases conceptuales y operativas. Métodos de intervención (pp.151199). Barcelona: PPU.

Sánchez Vidal, A. (2003). Investigación, acción y conflicto de lealtades psicológicas: El caso del sentimiento de comunidad. Apuntes de Psicología, 21(3), 459-473.

Svampa, M. (2013). Consenso de los Commodities y lenguajes de valoración en América Latina. Revista Nueva sociedad, 244, 30-47. Recuperado de: www.nuso.org,

Valles, M. S. (2003). Técnicas cualitativas de investigación social. España: Síntesis.

Universia Fundación. (2015). Disponible en http://noticias.universia.com.ar/

Vasilachis de Gialdini, I. (2009). Estrategias de investigación Cualitativa. España: Gedisa

Vergara Arias, M. (2009). Conflictividad urbana en la apropiación y producción del espacio público. El Caso de los Bazares Populares de Medellín. Revista Bitácora Urbano Territorial, Enero-Junio, 141-160.

Vommaro, P. (2013). Relaciones entre juventudes, políticas y culturas en la Argentina y en América Latina actuales: Miradas desde las formas de participación política de los jóvenes en movimientos sociales y desde las políticas públicas. En "Juventudes en la Argentina y América Latina: Cultura, política e identidades del siglo XX al XXI”, CONICET-CAICYT (http://cursos.caicyt.gov.ar), Argentina. 